
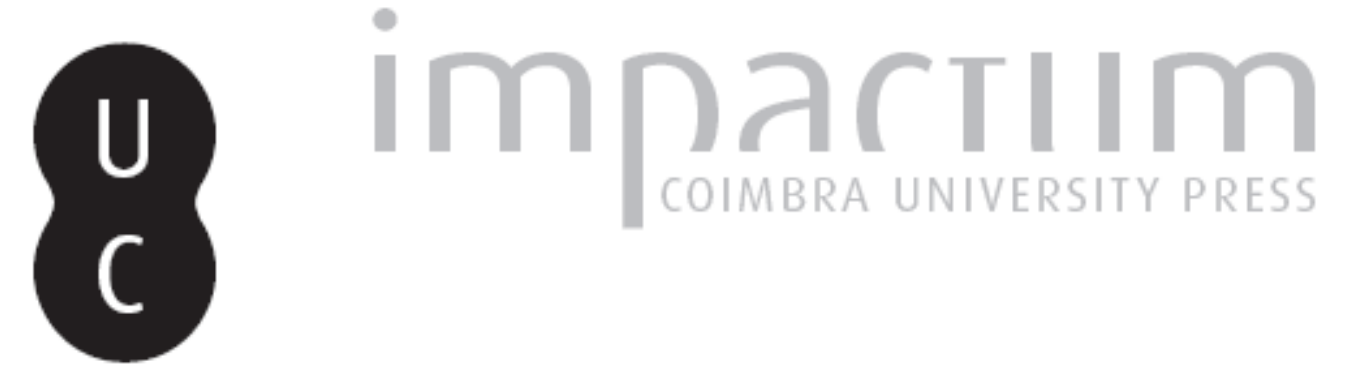

\title{
A Cava de Viriato num documento do século XVII
}

Autor(es): $\quad$ Vaz, João L. Inês

Publicado por: Faculdade de Letras da Universidade de Coimbra

URL persistente:

URI:http://hdl.handle.net/10316.2/37729

DOI:

DOI:http://dx.doi.org/10.14195/1647-8657_45_12

Accessed : $\quad$ 26-Apr-2023 13:46:53

A navegação consulta e descarregamento dos títulos inseridos nas Bibliotecas Digitais UC Digitalis, UC Pombalina e UC Impactum, pressupõem a aceitação plena e sem reservas dos Termos e Condições de Uso destas Bibliotecas Digitais, disponíveis em https://digitalis.uc.pt/pt-pt/termos.

Conforme exposto nos referidos Termos e Condições de Uso, o descarregamento de títulos de acesso restrito requer uma licença válida de autorização devendo o utilizador aceder ao(s) documento(s) a partir de um endereço de IP da instituição detentora da supramencionada licença.

Ao utilizador é apenas permitido o descarregamento para uso pessoal, pelo que o emprego do(s) título(s) descarregado(s) para outro fim, designadamente comercial, carece de autorização do respetivo autor ou editor da obra.

Na medida em que todas as obras da UC Digitalis se encontram protegidas pelo Código do Direito de Autor e Direitos Conexos e demais legislação aplicável, toda a cópia, parcial ou total, deste documento, nos casos em que é legalmente admitida, deverá conter ou fazer-se acompanhar por este aviso.

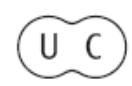




\section{CONIMBRIGA}

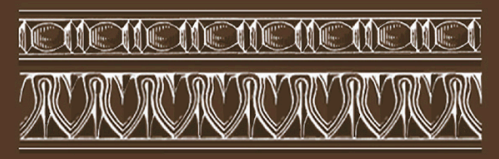

INSTITUTO DE ARQUEOLOGIA

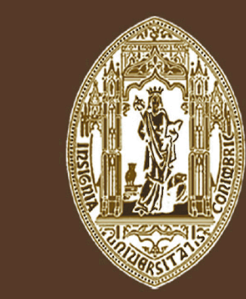

VOLUME XLV - 2006

FACULDADE DE LETRAS UNIVERSIDADE DE COIMBRA 
JoÃo L. INÊS VAZ

Universidade Católica Portuguesa - Pólo de Viseu

email: jlivaz@gmail.com

\section{A CAVA DE VIRIATO NUM DOCUMENTO DO SÉCULO XVII "Conimbriga" XLV (2006) p. 199-209}

Resumo: O autor analisa um desenho da Cava de Viriato que aparece intercatado num manuscrito sobre Viseu, escrito provavelmente em 1638. É o desenho mais antigo que se conhece da Cava e mostra o estado em que se encontrava há mais de três séculos e meio.

Começa por lembrar uma obra anterior que se refere a Viseu na época romana em que parecem basear-se todas as obras publicadas posteriormente e nomeadamente a de 1638 de João de Pavia, objecto deste trabalho.

Faz-se a análise minuciosa do desenho, talude a talude e a comparação entre a que era a Cava nessa época e o estado em que se encontra agora, concluindo-se que o estado de degradação era já bastante acentuado, mas sem a ocupação urbana que hoje apresenta.

ABSTRACT: The author analyses a drawing of the "Cava de Viriato" intercalated in a manuscript about Viseu probably written in 1638. It's the oldest known drawing of "Cava de Viriato" and it shows the state it was in over three and a half centuries ago.

He starts out by remembering a previous work that refers to Viseu in the roman ages and seems to be the basis for all the works published since, mainly the one by João de Pavia in 1638, object of this paper. A meticulous analysis of the drawing is made, wall-by-wall and also the comparison between what the "Cava de Viriato" was at the time and the state it is in today, concluding that the degradation state was already quite accentuated but without the urban occupation it presents today. 
(Página deixada propositadamente em branco) 


\section{A CAVA DE VIRIATO NUM DOCUMENTO DO SÉCULO XVII*}

Quero começar por fazer uma saudação especial aos dois grandes Mestres que tive nesta casa, os Professores Doutores Jorge Alarcão e José d'Encarnação que me iniciaram nas coisas arqueológicas e que ao longo dos anos que levo de investigação sempre me continuaram a dispensar a sua amizade e me incentivaram a prosseguir. $\mathrm{O}$ meu bem bem-haja, à maneira beirã.

$* * *$

A recente edição de um manuscrito sobre Viseu que se mantinha inédito desde o século XVII trouxe, mais uma vez, à luz do dia o desenho mais antigo da Cava de Viriato ${ }^{1}$, em Viseu. É, pois, sobre esse desenho que iremos incidir a nossa atenção nesta reflexão que aqui trazemos neste dia comemorativo dos cinquenta anos do Instituto de Arqueologia ${ }^{2}$.

As mais antigas referências escritas a Viseu na época romana relacionam-se, como não podia deixar de ser, com a figura de Viriato,

* O presente texto é a adaptação de uma conferência que o autor apresentou na Universidade de Coimbra por ocasião do Dia do Antigo Aluno, integrado nas comemorações dos 50 anos do Instituto de Arqueologia.

1 Sobre a Cava de Viriato já se escreveram muitas centenas de páginas que não vamos aqui repetir. Um levantamento de toda a bibliografia publicada até 1993 e uma síntese de todas as posições até então assumidas, pode ver-se em Vaz, 1997, p. 359-367.

2 João de Pavia, Descrição da Cidade de Viseu - Suas antiguidades e cousas notáveis que contém em si e seu bispado, composta por um natural, Edição e estudo literário de Sara Augusto, Viseu, 2002.

A primeira publicação do desenho foi feita por Isabel Monteiro, Os Judeus na Região de Viseu, Viseu, 1997, encarte entre as páginas 94 e 95.

Conimbriga, 45 (2006) 199-209 
a Cava de Viriato e as inscrições romanas que surpreendiam aqueles que as encontravam e procuravam decifrar (Est. I). Em Viseu, como noutras partes, foi o achado dessas "antigualhas" que fez com que se mantivesse viva a memória dos antigos e sobretudo dos Romanos.

Podemos marcar 1632 como o ano em que começou o registo das antiguidades romanas de Viseu quando Manoel Botelho Ribeiro Pereira, um historiógrafo local escreveu os Diálogos Moraes e Políticos que se constitui como a mais antiga obra de referência até agora conhecida e publicada sobre a cidade e região de Viseu ${ }^{3}$. É curioso que já neste século XVII haja a ideia de que Viseu tinha sido o centro regional mais importante na antiguidade e por isso Botelho Pereira fala de toda a área em que a cidade se integra, ou seja, aquilo que é hoje praticamente o Distrito de Viseu.

Botelho Pereira faz a recolha dos elementos aparecidos na cidade, nomeadamente os letreiros, atribui a construção da Cava aos Romanos e fala dos vestígios que à volta da cidade apareciam. A verdade é que a leitura que faz das inscrições romanas que ele viu permite-nos quase sempre a sua reconstituição e os lugares de que nos fala, sempre que se puderam visitar, são confirmados como lugares com vestígios romanos. Apesar da sua imaginação fértil na reconstituição dos factos, as descrições que nos deixou têm sido de extrema valia. Referimo-nos a este escrito de Botelho Pereira antes de entrarmos propriamente no tema porque consideramos esta obra inspiradora de outras que lhe sucederam no tempo.

Pouco depois, em 1638, João de Pavia escreveu um poema épico em honra de Viseu, Descrição da Cidade de Viseu Suas Antiguidades e Cousas Notáveis que contém em si e seu Bispado, composta por um Natural, poema em 10 cantos que nos parece largamente baseado na obra anterior de Botelho Pereira. Tratando-se de uma obra literária encomiástica, não tem grande interesse para a História e a Arqueologia, mas no canto II apresenta algumas estrofes em que se fala da Cava e um desenho colorido onde coloca as suas entradas, estradas e medidas.

3 Manoel Ribeiro Botelho Pereira, Diálogos Morais e Políticos, Viseu, 1955. 


\section{Canto II}

42

Ao Norte não mui longe da cidade Um sítio se descobre raso e plano Cercado de alta cava e na vontade Cava lhe chama o povo vil profano. Uns dizem que na velha antiga idade Serviu de alojamento do romano Exército, que guerra, fera insana Fazia à forte gente lusitana.

43

Outros que no princípio edeficada Sendo a nobre cidade de Viseu No sítio, e de alta cava rodeada Obra que lhe ordenava o povo seu, Dos romanos enfim fora assolada, Com o nome que a fama antiga lhe deu Por falta das antigas escrituras, Usando de adequadas conjecturas.

\section{4}

Não falta quem concorde, afirme e diga das opiniões tomando fundamento, que fora o sítio plano e cava antiga do exército romano alojamento, despois que afeiçoada a gente e amiga edificar ali tivera intento cidade, como mostra o largo muro, que foi principiado forte e duro.

Nestas estrofes, João de Pavia faz-se eco das tradições que corriam sobre a Cava com as confusões próprias de uma tradição oral popular. Não se sabia quando tinha sido fundada nem por quem, se pelos Romanos se por outro povo anterior (“... "a forte gente lusitana”...), se antes ou depois da presença romana no local. 
A presença romana na cava é uma certeza, mas se foi cidade romana iniciada ou simples acampamento militar (... "do exército romano alojamento"...), ideia que se repete nas estrofes 42 e 44, já não se sabia.

João de Pavia não nos diz também os nomes que corriam para a cidade situada dentro da Cava, dizendo simplesmente que eram "adequadas conjecturas". Seria já o nome de Vacca que ele vai depois usar na planta, como veremos abaixo?

Deverá salientar-se o facto de João de Pavia nunca se referir, no poema, à cava como "Cava de Viriato", nem a relacionar com o chefe lusitano, mas chamar-lhe simplesmente "Cava". 4

Podemos dizer que estas interrogações de João de Pavia são questões que continuam em aberto e que, quase três séculos passados se não resolveram.

Entre as páginas 32 e 33 do seu manuscrito, João de Pavia inclui um desenho que se constitui como o desenho conhecido mais antigo deste monumento. (Est. II).

Debrucemo-nos um pouco sobre o desenho, pois a sua divulgação foi feita até agora apenas numa obra de carácter literário e não histórico ou arqueológico.

Apesar de, no texto, hesitar em atribuir a fundação da cava aos Romanos ou aos Lusitanos, na legenda principal do desenho, o autor não hesita em chamar-lhe "Cava de Viriato" e, em subtítulo, faz-se eco da tradição de que ali teria estado instalada a cidade de Vaca: Cava de Viriato / sitio da Antigua cid.e de Vaca. (Est. III)

Além da atribuição popular da construção da Cava a Viriato, a tradição escrita de Viseu diz que em várias ocasiões a Cava terá servido de refúgio das populações que para ali fugiam em épocas de perigo. Assim, teria sido no tempo dos Lusitanos e Romanos e assim teria sido nos tempos medievais. Quando Fernando Magno reconquistou Viseu, a cidade estava desprovida de muralhas e, então, ter-se-ia fundado dentro da Cava uma nova cidade face ao assédio permanente dos árabes (Neves, 1893, p. 41-45). A cidade antiga estaria desprotegida e com as muralhas

4 Sobre este assunto da relação da Cava e de Viseu com Viriato, ver o trabalho do autor Viseu e Viriato: a cidade e o mito, a publicar brevemente nas Actas da VII Mesa Redonda Internacional sobre a Lusitânia Romana, Cascais, Novembro de 2004.

Conimbriga, 45 (2006) 199-209 
derrubadas e na cava a população ficava protegida das investidas árabes pelos altos muros que a rodeavam e pelo fosso da mesma.

Essa cidade chamar-se-ia a cidade de Vacca e daí o nome que João de Pavia dá à Cava.

A cava tinha cinco entradas, localizadas a nordeste, noroeste, este, sudeste e sudoeste, apesar de João de Pavia só apelidar três como portas. As portas são viradas a S. Tiago (Santiago), Santa Luzia (S.ta Luzia do monte) e Aguieira (Aguieyra).

A primeira é a "porta da traiçam" e está virada à Aguieira, pequeno lugar hoje integrado na cidade. Localiza-se a sudoeste da Cava. É ainda hoje a principal entrada na Cava, para quem vem da cidade.

A segunda porta, apelidada de "D. Jorge", está virada a noroeste, a "Santa Luzia". É curioso que esta porta seja de D. Jorge, pois o que sabemos é que existiu na Cava uma capela dedicada a S. Jorge. Será que a capela já tinha desaparecido na data em que João de Pavia escreveu e apenas havia a recordação vaga de algo relacionado com o nome Jorge e daí esta porta ser chamada de D. Jorge em vez de S. Jorge?

A porta 3 é virada a $S$. Tiago e Esculca e não tem qualquer nome identificativo. Junto do lugar onde se abria esta porta, ainda hoje se mantém uma entrada. Actualmente, no sítio da porta, o fosso desapareceu completamente e o talude mal se distingue.

As outras duas entradas que João de Pavia anota, não as considera como portas e não lhes dá qualquer nome. São ambas viradas a oriente, uma mais próxima da igreja da Senhora da Conceição e outra para a ponte da Ribeira (pontam).

A entrada sobre um pontão localizado sobre o Rio do Pintor ou Ribeira de S. Tiago, ainda hoje dá entrada para a rua do Picadeiro, que é uma rua totalmente interior da Cava. A rua actual segue próximo de uma das estradas que João de Pavia aponta ligando a porta 3 e a outra entrada virada à Senhora da Conceição.

Um atalho entre as duas entradas referidas desapareceu quase completamente.

A entrada localizada frente à igreja da Senhora da Conceição conduzia para o interior da Cava havendo um atalho que atravessava toda a Cava. Este atalho desapareceu e hoje não é possível atravessar a cava de uma ponta à outra, de sudeste para noroeste. Apenas se mantiveram os extremos do atalho, ou seja o início e a parte final. Assim, já no interior da cava é possível partir de noroeste, da segunda porta ou "porta de 
D. Jorge" e chegar ao meio da cava mas depois é preciso regressar atrás. Do outro lado, de sudeste, é possível chegar até algumas dezenas de metros dentro da Cava, mas os dois troços não ligam, pois no meio existem terrenos de cultivo particulares.

Além dos atalhos, há ainda duas estradas que são representadas por João de Pavia e que correspondem hoje à rua dos Heróis Lusitanos, do lado ocidental e à rua do Picadeiro, no lado oriental.

Vê-se assim que, em termos de estradas e caminhos interiores, os que existem hoje são os que já existiam no século XVII, mas o atravessamento longitudinal desse século é impossível de se fazer hoje.

Outro dado que devemos observar neste desenho de João de Pavia é o estado dos fossos. Os fossos são numerados consoante os lados do polígono, começando de sudeste para noroeste e diz-se que estão secos ou com água. Assim temos:

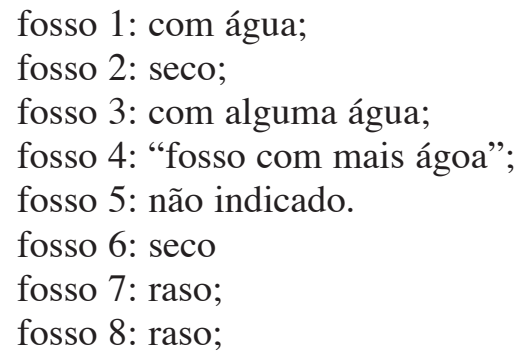

Verificamos assim que, em 1638, o fosso da cava estava arrasado apenas em dois lados, os virados a oriente. São estes dois lados, não só do fosso como da própria Cava, que hoje desapareceram quase completamente.

O segundo fosso, que João de Pavia apresenta como seco, é onde hoje se encontra a estátua de Viriato. Este troço do fosso e respectivo talude teriam sido objecto de obras quando, na segunda metade do século XIX o talude foi alteado e no topo criado um passeio público e o fosso acabado de arrasar (Neves, 1893, p. 41-45).

O terceiro fosso, que ainda tinha alguma água no século XVII, foi arrasado e no ângulo deste fosso e lado abria-se a porta da traição no mesmo lugar onde hoje se abre o talude para deixar entrar o trânsito na cava. 
O quarto fosso era o que tinha mais água e ainda hoje mantém água permanentemente. Aqui, pode-se observar ainda a grandiosidade da cava, com o muro mais levantado e fosso mais profundo.

O sexto fosso está seco e o sétimo e oitavo arrasados.

Vemos assim que, em relação aos fossos, a situação do século XVII se deteriorou tendo sido arrasados mais alguns. Os que se encontravam arrasados já quase desapareceram, mal se notando actualmente, os que estavam secos foram aproveitados para abrir novas estradas ou destinados a outras funções e os que tinham água, água continuam a ter.

A contornar a Cava, vindo da cidade, João de Pavia coloca uma estrada que corresponde, pela sua orientação, à Estrada Velha de Abraveses que passava junto da igreja da Senhora da Conceição.

Esta estrada seria a continuação da velha via romana que saía pela porta localizada no extremo norte do cardo da cidade romana, por alturas do actual Largo Mouzinho de Albuquerque ou das Freiras e que era ladeada de uma importante necrópole localizada na actual Avenida Emídio Navarro (Vaz, 1997, p. 356-357).

Deve ainda salientar-se um outro elemento que João de Pavia coloca no seu desenho. Na abertura que dá entrada aos atalhos, localizada a nordeste, aparece uma seteira. Ora, esta indicação coincide por um lado, com a travessia do "rio do pintor" que coloca ali mesmo em frente, num pontão e, por outro com o sítio onde não existia fosso por estar razo. Isto parece indicar alguma preocupação de defender aquela zona.

Uma das tradições de que o próprio autor se faz eco é de que a Cava teria sido uma fortaleza e ainda hoje essa tradição se mantém e diz-se também que os muros da Cava eram cobertos por pedras que foram retiradas para construir o convento de S. Francisco de Orgens. Diz-se mesmo que um alvará de D. Afonso V teria autorizado os monges a retirarem as pedras das portas da Cava para as levarem para o convento que entretanto estavam a construir em S. Martinho de Orgens. Nada de concreto existe além dessa tradição. Mas a indicação do desenho é a prova de que pelo menos algumas partes da Cava tinham pedra a coroar os taludes onde estavam implantadas seteiras.

Interpretando o desenho e a tradição, penso que devemos concluir que a Cava continuava a ser considerada uma verdadeira fortaleza nesta época e que o fosso, seco ou com água, continuava a ser considerado 
como uma defesa do seu interior. Onde não existia fosso, fez-se um reforço dos taludes construindo seteiras no seu topo. Deverá assinalarse que ainda hoje esta entrada, que permite a entrada na cava através da rua do Coval, está protegida por um paredão em pedra de cada lado da rua.

A designação de porta da traição atribuída à porta situada a sudoeste parece-nos confirmar também que a cava continuava a ser considerada como uma fortaleza nesse século.

O pontão que atravessa o rio conduz a um caminho que leva para S. Tiago, no exterior da muralha e que foi substituído pela actual estrada que leva para S. Tiago e Esculca.

O perímetro da Cava é medido em passos, mas João de Pavia apresenta apenas sete medidas, embora desenhe um octógono. No total mede 1733 passos. Ora, se pensarmos que cada passo corresponderá sensivelmente a $80 \mathrm{~cm}$., teremos 1386 metros, o que daria 173 metros de lado. É evidente que, a este nível, João de Pavia se enganou pois não só esqueceu um lado, como certamente errou ao percorrer a cava para a medir.

A Cava actual tem uma área interna de cerca de 32 hectares e mais de dois quilómetros de perímetro, medindo cada lado cerca de 270 metros.

Se considerarmos a área pelo limite externo do fosso, dá-nos cerca de 36 hectares, pensando que o fosso teria cerca de 16 metros de largura e o talude, na base, cerca de 34 metros, o que perfaz cerca de 52 metros.

Cotejando este desenho de 1638 com a cava actual verificamos algumas semelhanças e também diferenças significativas:

- continuam a existir cinco entradas e saídas, o que significa que, apesar da destruição destes três séculos, a estrutura base manteve-se;

- actualmente só estão de pé quatro lados;

- apesar das alterações que se verificaram, os caminhos actuais do interior da cava aparecem já na planta de João de Pavia, o que nos leva a pensar que esses mesmo caminhos retomarão percursos mais antigos ainda;

- o atalho que atravessava a cava de uma ponta à outra desapareceu, permanecendo apenas os extremos;

- o fosso está muito menos visível que no século XVII.

Em conclusão, se o desenho de João de Pavia não nos traz novos elementos que nos elucidem sobre os enigmas que a Cava de Viriato 
continua a esconder, a verdade é que não deixa de constituir uma mais valia para o estudo da cidade de Viseu e sobretudo do seu monumento mais significativo que é a Cava de Viriato.

\section{BIBLIOGRAFIA:}

Neves, 1893= Henrique das Neves, A Cava de Viriato. Notícia desciptiva e Critico-Historica, Figueira da Foz.

Pereira, 1955 = Manuel Botelho Ribeiro Pereira, Diálogos Morais e Políticos, Viseu, 1955, p. $95-100$.

VAZ, 1997 = João L. Inês Vaz, A civitas de Viseu - Espaço e Sociedade, Comissão de Coordenação da Região Centro, Coimbra.

htttp://www.it-geo.pt 
EsT. I

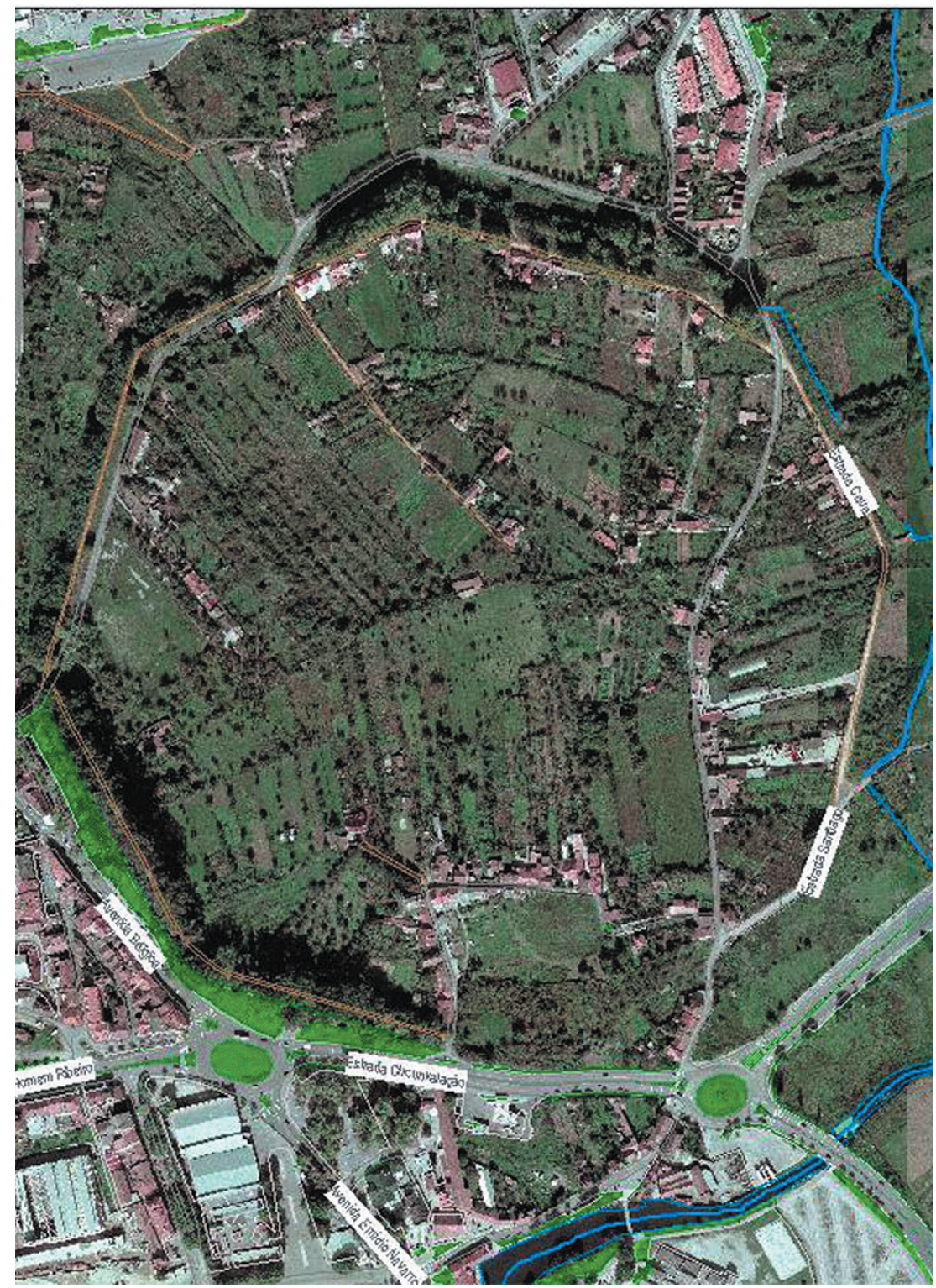


EST. II

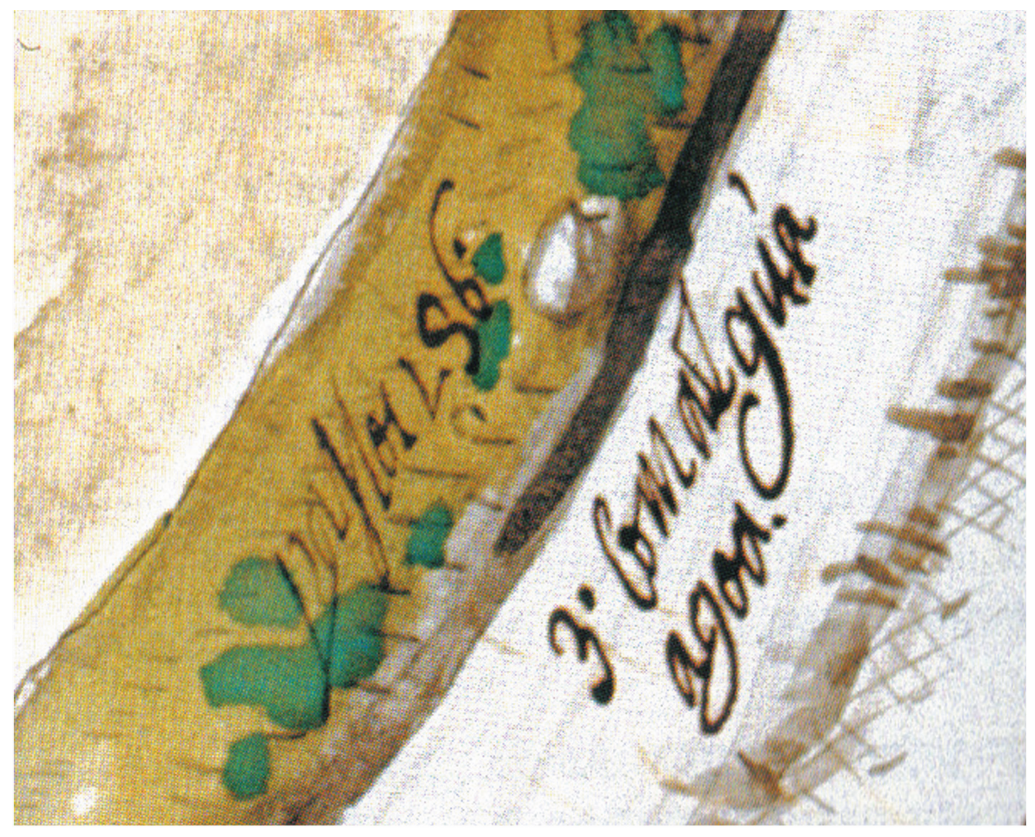

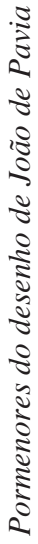

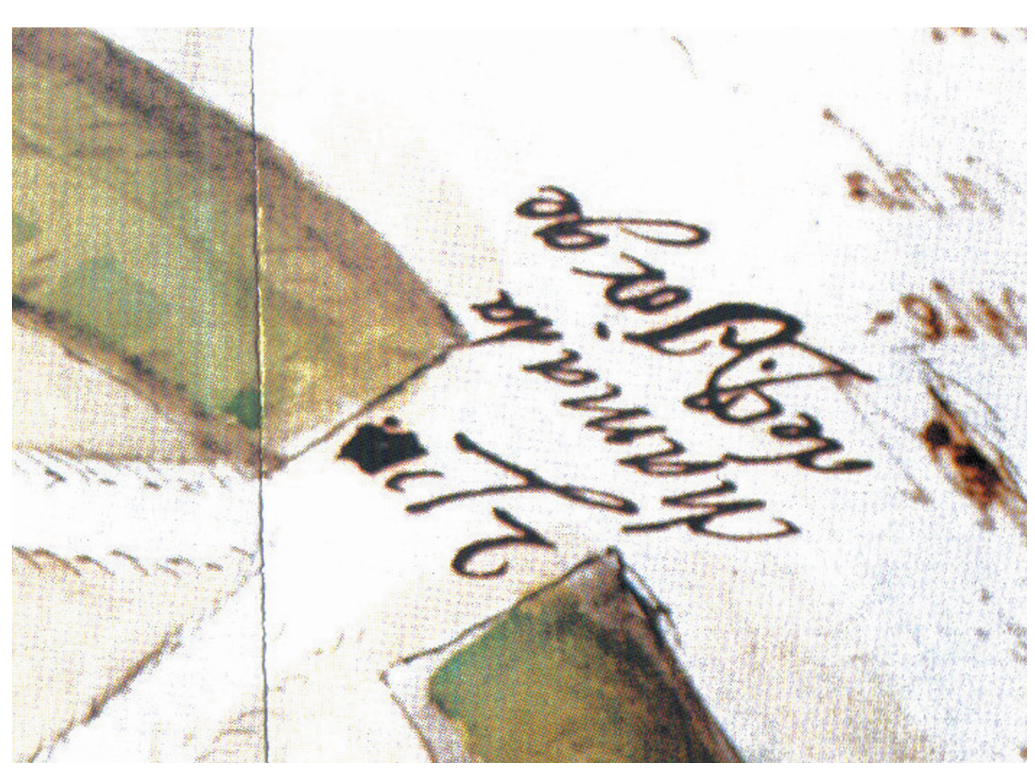


EsT. III
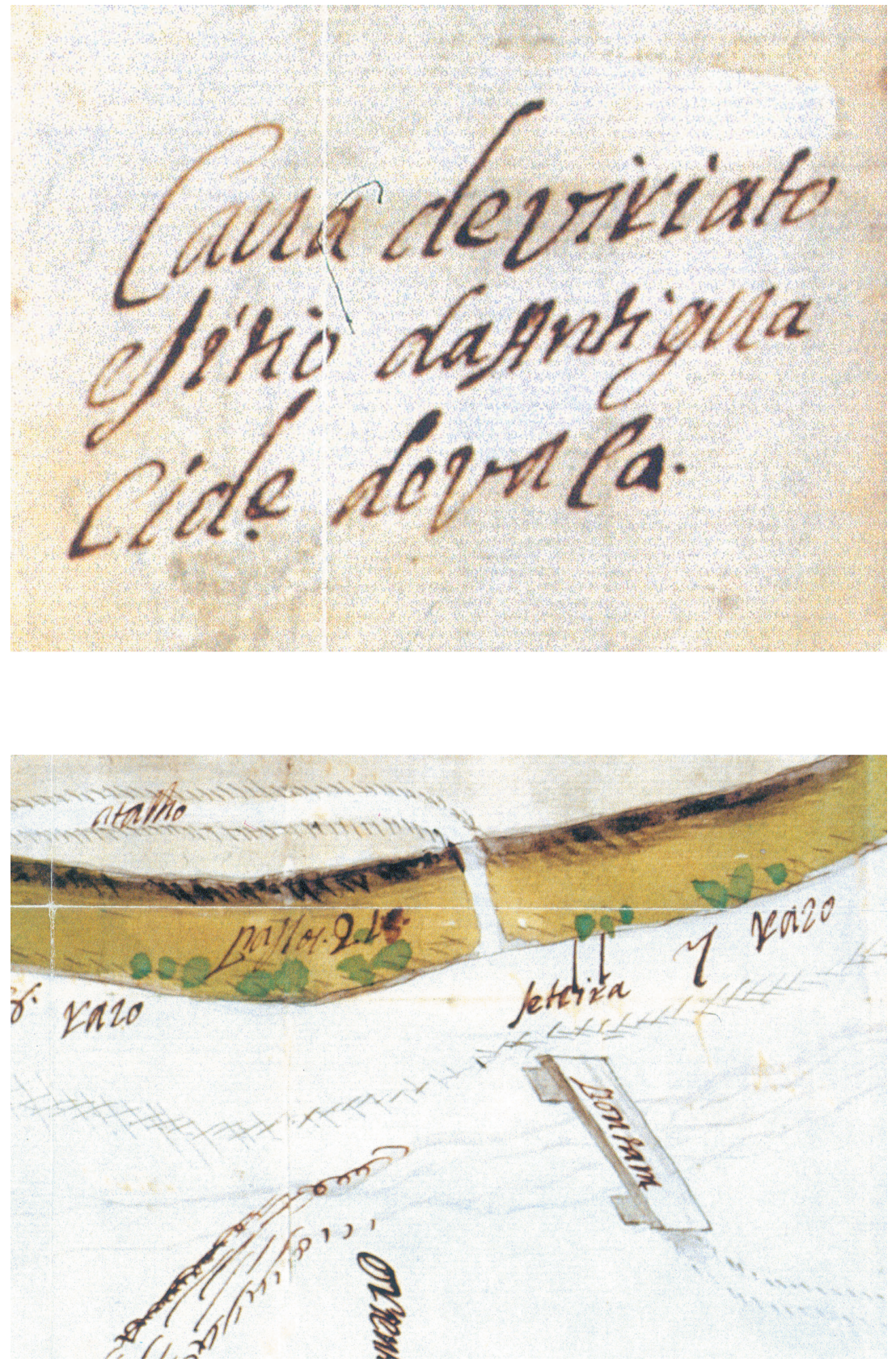

Pormenores do desenho de João de Pavia 


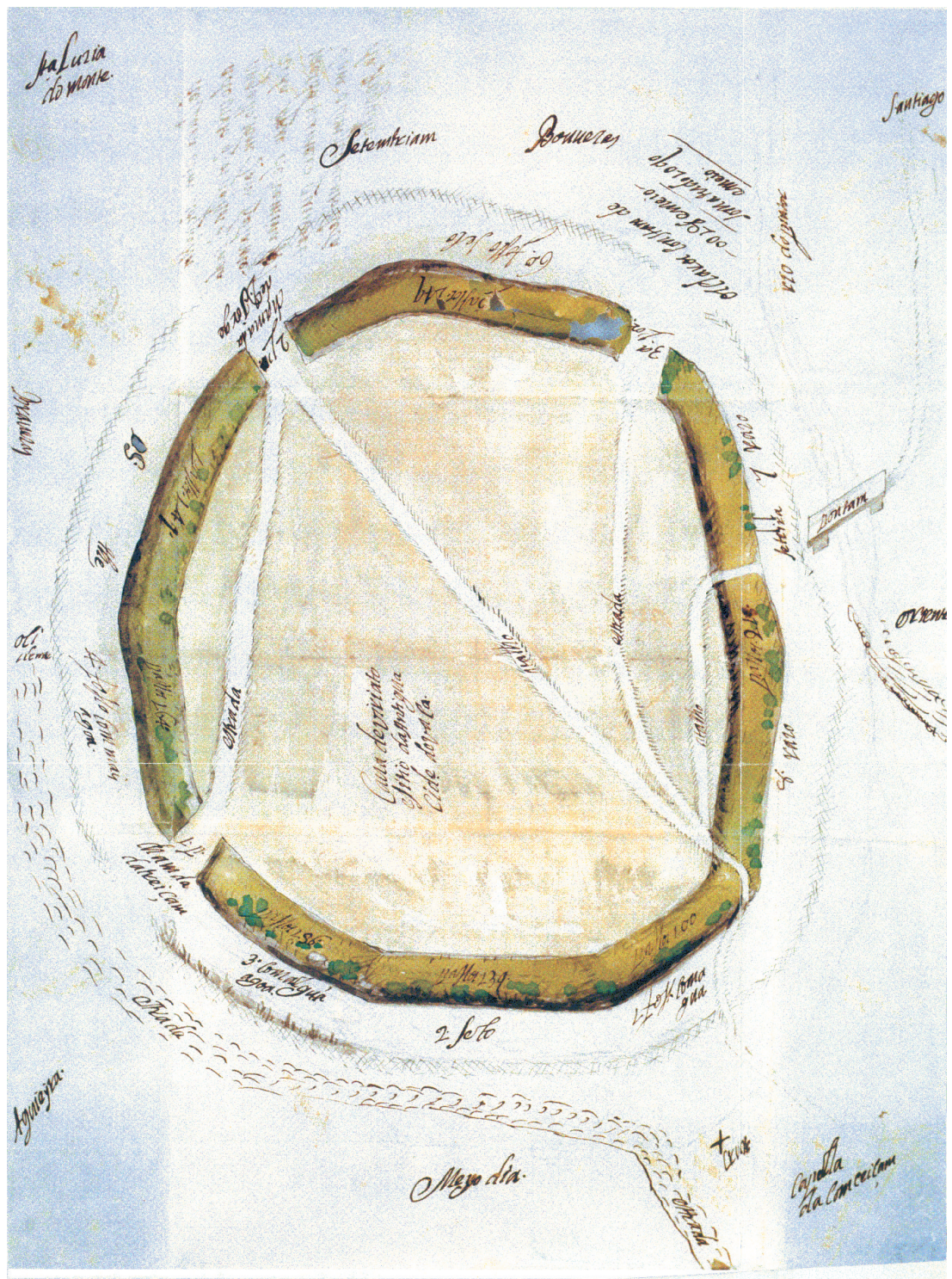




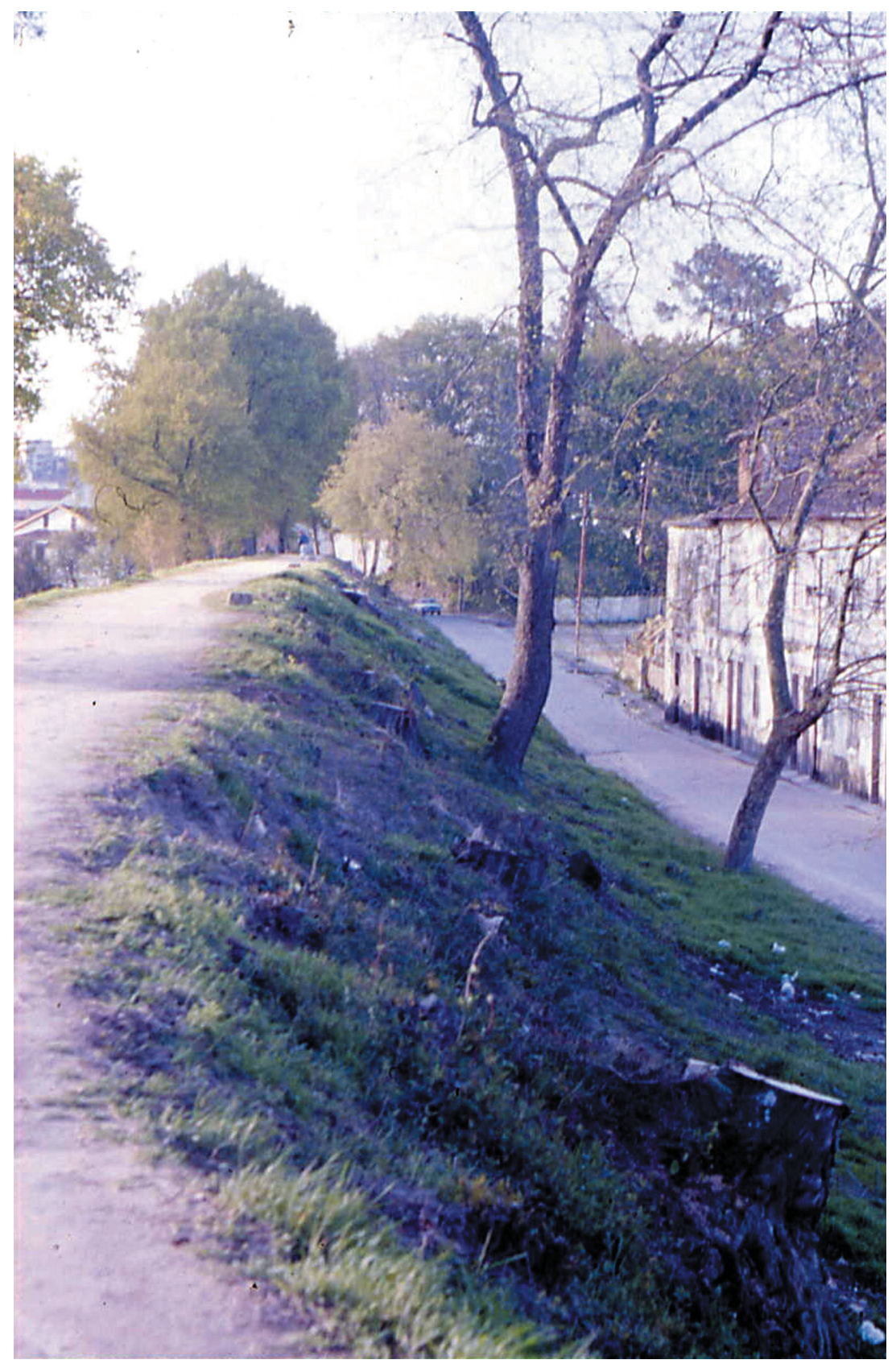

